\title{
Structural Analysis of the Aluminum Cylinder Head for a High-Speed Diesel Engine
}

\author{
Alexandre Schalch Mendes \\ MWM INTERNATIONAL Motores \\ Ademar de Azevedo Cardoso \\ GAC Soluções Ltda.
}

Copyright $@ 2007$ Society of Automotive Engineers, Inc

\begin{abstract}
This paper presents the methodology for structural analysis of a high-speed Diesel engine aluminum cylinder head for Pick-up application, considering the finite element method. As boundary conditions, it was considered the loads from the bolts tightening process, combustion peak pressure, and thermal loading. The stresses generated during the assembly of the valve seats and valve guides were also evaluated. The valve train dynamic loads were not analyzed or considered in this paper, due to its negligible effects at the critical regions.
\end{abstract}

The FE model contains the upper part of the crankcase and the entire cylinder head. Heat transfer coefficients at the water jackets were obtained from a CFD calculation and used at the heat transfer analysis to evaluate the thermal stresses.

The residual stresses generated by the casting and manufacturing processes, as well the heat treatments for the alloy mechanical properties improvements, are also considered on this analysis.

Fatigue safety factor shall be evaluated considering the critical loading cycle, focusing the reliability of the component at severe operational conditions. The cylinder head design shall consider its application, taking into account high combustion peak pressures to attempt the current environmental legislation and higher engine output power required by modern vehicular applications.

\section{INTRODUCTION}

Nowadays, due to technical and commercial requirements, the internal combustion engines must operate with higher cylinder pressures and the design of the components shall be optimized for the best performance.
The modern calculation methods, allow a precise calculation of the stresses at the parts, as well the evaluation of the fatigue strength. By this way, it is possible to determine safety factors that guarantee a sufficient reliability to avoid failures at the field and over-sizing of the components.

To calculate the stresses in the cylinder head it is necessary to determine the actuating loads during the critical operational cycles. The load cases that will be considered at the analyses are: The assembly loads, combustion peak pressure and the thermal stresses.

On next section, it will be described all considered steps, from the finite element model creation up to fatigue safety factor evaluation.

\section{FINITE ELEMENT MODEL}

The entire cylinder head was modeled considering solid parabolic tetrahedron elements. The upper part of the crankcase was also modeled to consider the actual stiffness of the assembling.

As the analysis is focused only on the component structural strength verification, the cylinder head gasket is considered presenting linear properties behavior.

It was also considered that, after the bolts tightening process, the interface region between the crankcase and the cylinder head will not be decoupled after the introducing of the other load cases, simulating a perfect glue contact at the gas sealing regions of the gasket.

Due to these considerations, this model is not indicated for gas, water and oil sealing investigations, as the same way, it can not be considered for the determination of the micro-movements between the parts for fretting 
prediction. A nonlinear gasket model shall be used for these purposes.

Generally, the loads of the valve train system are not critical for the cylinder head structure and by this way, these loading were not introduced in the model.

The next picture shows the FE model used for the stress analysis.

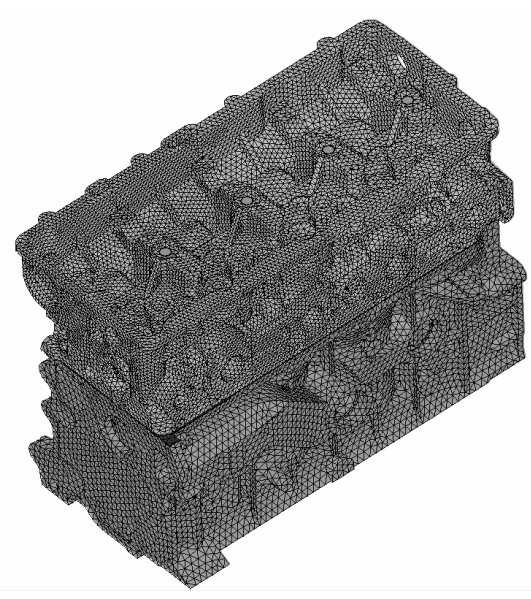

Figure 1: Finite element model.

\section{BOUNDARY CONDITIONS}

RESTRAINTS - The displacements in all directions were restrained at the region of the crankcase main bearings.

PEAK CYLINDER PRESSURE - The cylinder head was analyzed at over-pressure condition. Generally, this is the most critical mechanical loading for the component. The figure 2 presents a typical way for the combustion pressure application at the model.

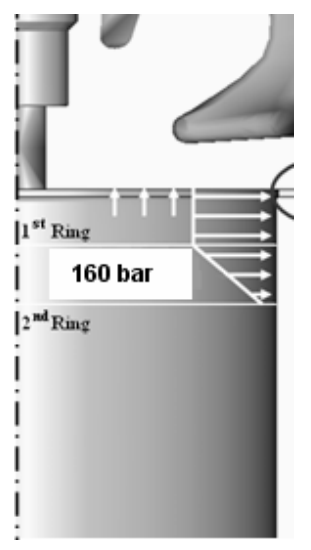

Figure 2: PCP load application.
The distance form top dead center (TDC) of the piston to the position where the maximum cylinder pressure occurs, can be determined by the following equation:

$$
S_{k}=r \cdot\left[1+\frac{L}{r}-\cos (\alpha)-\sqrt{\left(\frac{L}{r}\right)^{2}-\operatorname{sen}^{2}(\alpha)}\right]
$$

Where: $r=$ crank radius

$$
\begin{aligned}
& \mathrm{L}=\text { connecting rod length } \\
& \alpha=\text { crank angle }
\end{aligned}
$$

The intake and exhaust valves were not considered in the finite element model. The combustion load due to the cylinder internal pressure was applied at the valve seats contact surfaces, considering the projected area of the valves. The preload of the valve springs was also applied.

BOLTS ASSEMBLY LOAD - The tightening force of the cylinder head bolts were introduced into the model as a preload at the beam elements. This load can be considered as being the nominal tightening force, in this case, $89880 \mathrm{~N}$.

THERMAL LOADING - By the proposed formulation on this section, it is possible to estimate the convection coefficients and surrounding temperatures that are necessary to compute the nodal temperatures in all regions of the FE model.

These calculated values result in accurate nodal temperatures. But generally, it is recommended to measure the actual temperatures to validate the theoretical input.

The convection coefficients $\left(h_{c}\right)$ for the crankcase and cylinder head surfaces can be determined according to the following methodology. To obtain more information, see reference [1].

External surfaces of the cylinder head and crankcase Forced convection formulation shall be considered for these regions.

Reynolds index:

$$
\operatorname{Re}=\frac{\rho \cdot \mathrm{v} \cdot L}{\mu}
$$

Convection coefficient:

$$
h_{c}=\frac{0,036 \cdot \operatorname{Pr}^{0,33} \cdot \operatorname{Re}^{0,8} \cdot \mathrm{k}}{\mathrm{L}}
$$

Exhaust and intake ducts - When a CFD analysis for the gas side is not available, it is possible to estimate the convection coefficients of these regions, as follow: 
Sound velocity:

$$
c=\sqrt{\gamma \cdot R \cdot T}
$$

Mach index (shall not exceed 0,6):

$$
Z=\frac{A_{p}}{n \cdot A_{v(i, e)}} \cdot \frac{\mathrm{v}_{m}}{C_{v(i, e)} \cdot c}
$$

Mean flow coefficient of the intake valve:

$$
C_{i}=1,45 \cdot \frac{l_{i}}{d_{i}}
$$

Mean flow coefficient of the exhaust valve:

$$
C_{e}=(0,6 \ldots 1,0) \cdot C_{i} \cdot\left(\frac{d_{i}}{d_{e}}\right)^{2}
$$

Gas / Air speed:

$$
w=Z \cdot c
$$

Reynolds index:

$$
\operatorname{Re}=\frac{\rho \cdot w \cdot L}{\mu}
$$

Hydraulic diameter:

$$
D_{h}=\frac{4 \cdot A}{P}
$$

Convection coefficient:

$$
h_{c}=\frac{0,023 \cdot\left[1+\left(\frac{D h}{L}\right)^{0,7}\right] \cdot \operatorname{Pr}^{0,33} \cdot \operatorname{Re}^{0,8} \cdot \mathrm{k}}{\mathrm{Dh}}
$$

Note: All physical properties shall be determined at mean convective film temperature $\left(\mathrm{T}_{\mathrm{f}}\right)$ :

$$
T_{f}=\frac{T_{b}+T_{s}}{2}
$$

Where:

$\mathrm{T}_{\mathrm{b}}=$ fluid mixture temperature
$\mathrm{T}_{\mathrm{s}}=$ average surface temperature
$\mathrm{T}_{\infty}=$ environmental temperature
$\mathrm{T}=$ absolute

$\rho=$ density of the fluid

$\mu=$ dynamic viscosity

$\mathrm{k}=$ thermal conductivity

$\operatorname{Pr}=$ Prandtl number

$\mathrm{L}=$ characteristic length / duct length

$\mathrm{v}=$ fluid speed

$\mathrm{A}=$ duct area

$\mathrm{A}_{\mathrm{p}}=$ piston area

$\mathrm{A}_{\mathrm{v}}=$ valve area (intake or exhaust)

$l_{i}=$ intake valve lift

$d_{\mathrm{i}}=$ intake valve diameter

$d_{\mathrm{e}}=$ exhaust valve diameter

$\mathrm{n}=$ number of valves

$\mathrm{V}_{\mathrm{m}}=$ mean piston speed

$\mathrm{R}=$ universal gas constant

$\gamma=$ adiabatic exponent of real gases $=c_{p} / c_{v}$

$\mathrm{P}=$ wet perimeter

$\mathrm{Q}=$ volumetric flow

Cylinder gas side (Hohenberg equation) - See reference [2] for detailed information.

Instantaneous cylinder volume:

$$
V(\alpha)=r \cdot\left[1+\frac{L}{r}-\cos (\alpha)-\sqrt{\left(\frac{L}{r}\right)^{2}-\operatorname{sen}^{2}(\alpha)}\right] \cdot \frac{\pi \cdot d^{2}}{4}+\mathrm{V}_{\mathrm{c}}
$$

Mean piston speed:

$$
\mathrm{v}_{\mathrm{m}}=2 \cdot \mathrm{n} \cdot \mathrm{s}
$$

Instantaneous cylinder pressure: $p=p(\alpha)$ could be measured by a pressure transducer and shall be considered as absolute pressure.

Instantaneous gas temperature in admission phase:

$$
\mathrm{T}(\alpha)=\frac{1-f}{1-\frac{1}{\gamma \cdot r c} \cdot\left[\frac{p_{e}}{p_{i}}+(\gamma-1)\right]} \cdot \mathrm{T}_{i}
$$

Instantaneous gas temperature in compression phase:

$$
\mathrm{T}(\alpha)=\mathrm{T}(\alpha-1) \cdot\left(\frac{\mathrm{V}(\alpha-1)}{\mathrm{V}(\alpha)}\right)^{\gamma-1}
$$

Instantaneous gas temperature in combustion phase:

$$
\mathrm{T}(\alpha)=\frac{\mathrm{p}(\alpha) \cdot \mathrm{V}(\alpha)}{\frac{8315}{\mathrm{M}} \cdot\left(\mathrm{m}_{\mathrm{air}}+\mathrm{m}_{\mathrm{fuel}}+\mathrm{m}_{\mathrm{res}}\right)}
$$


Instantaneous gas temperature in exhaust phase:

$$
\mathrm{T}(\alpha)=\mathrm{T}(\alpha-1) \cdot\left(\frac{\mathrm{p}(\alpha)}{\mathrm{p}(\alpha-1)}\right)^{\frac{\gamma-1}{\gamma}}
$$

Hohenberg equation:

$$
\mathrm{h}_{\mathrm{c}}(\alpha)=\mathrm{C}_{1} \cdot \mathrm{V}(\alpha)^{-0,06} \cdot \mathrm{p}(\alpha)^{0,8} \cdot \mathrm{T}_{\mathrm{m}}^{-0,4} \cdot\left(\mathrm{v}_{\mathrm{m}}+\mathrm{C}_{2}\right)^{0,8}
$$

Where:

$\alpha=$ crankshaft angle

$\mathrm{r}=$ crankshaft radius

$\mathrm{L}=$ connecting rod length

$\mathrm{d}=$ cylinder diameter

$\mathrm{V}_{\mathrm{c}}=$ compression space of the cylinder

$\mathrm{n}=$ engine speed

$\mathrm{s}=2 \cdot \mathrm{r}=$ piston stroke

$\gamma=$ adiabatic exponent of real gases $=\mathrm{c}_{\mathrm{p}} / \mathrm{c}_{\mathrm{v}}$

$\mathrm{p}_{\mathrm{i}}=$ intake absolute pressure

$\mathrm{p}_{\mathrm{e}}=$ exhaust absolute pressure

$\mathrm{T}_{\mathrm{i}}=$ intake absolute temperature

$r c=$ compression ratio

$f=$ residual gas fraction

$h=$ mass ratio water vapor to dry air

$\mathrm{Fr}=1 / \lambda=$ fuel-air ratio

$\mathrm{Fe}=$ stoichiometric fuel-air ratio for light Diesel

$m_{\text {air }}=$ air flow (measured at dynamometer)

$\mathrm{m}_{\text {air }}=$ air mass $=\frac{2 \cdot m_{\text {air }}}{\mathrm{n} \cdot 60 \cdot \mathrm{z}}$

$\mathrm{z}=$ number of cylinders

$\mathrm{m}_{\text {fuel }}=$ fuel mass $=\mathrm{Fr} \cdot \mathrm{Fe} \cdot \mathrm{m}_{\text {air }}$

$\mathrm{m}_{\text {res }}=$ residual gas mass $=\frac{-f \cdot\left(\mathrm{m}_{\text {air }}+\mathrm{m}_{\text {fuel }}\right)}{f-1}$

$\mathrm{M}=$ gas molecular weight:

$\frac{1+\mathrm{Fr} \cdot \mathrm{Fe}+\mathrm{h} \cdot(1-f)}{\left(\frac{1}{28,96}+\frac{\mathrm{Fr} \cdot \mathrm{Fe}}{170}+\frac{h}{18}\right) \cdot(1-f)+f \cdot\left(\frac{1+\mathrm{Fr} \cdot \mathrm{Fe}}{28,72}\right)}$

$\mathrm{T}_{\mathrm{m}}=$ average gas absolute temperature

Hohenberg coefficients: $C_{1}=130$

$$
\mathrm{C}_{2}=1,4
$$

The results of these calculations are presented at the next figures:

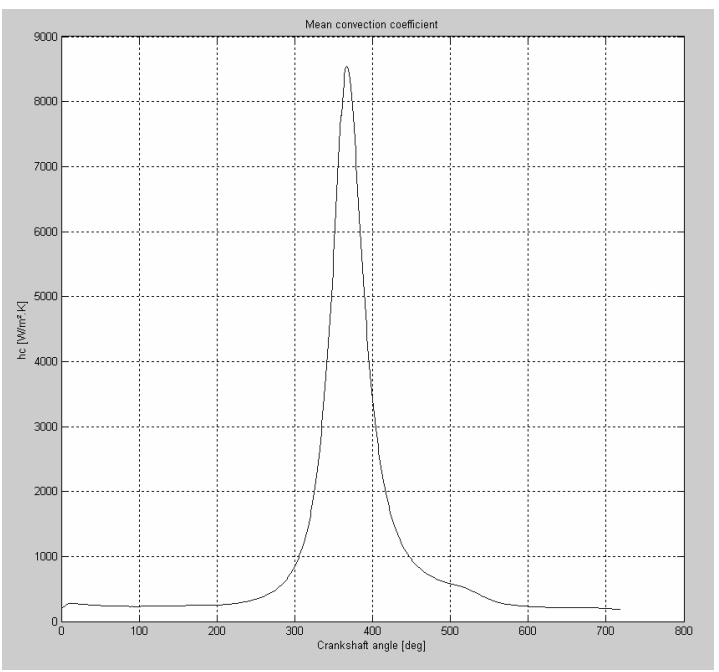

Figure 3: Mean convection coefficient $\left[\mathrm{W} / \mathrm{m}^{2} \mathrm{~K}\right]$.

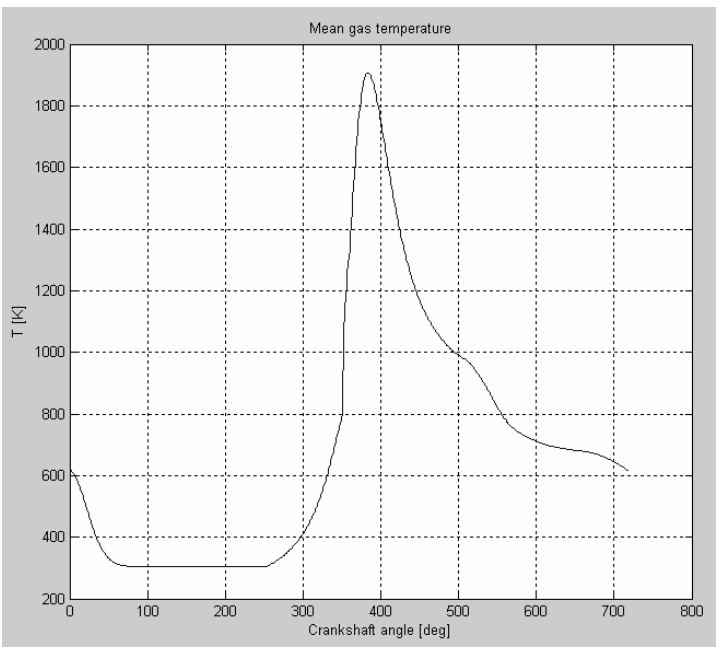

Figure 4: Mean gas temperature [K].

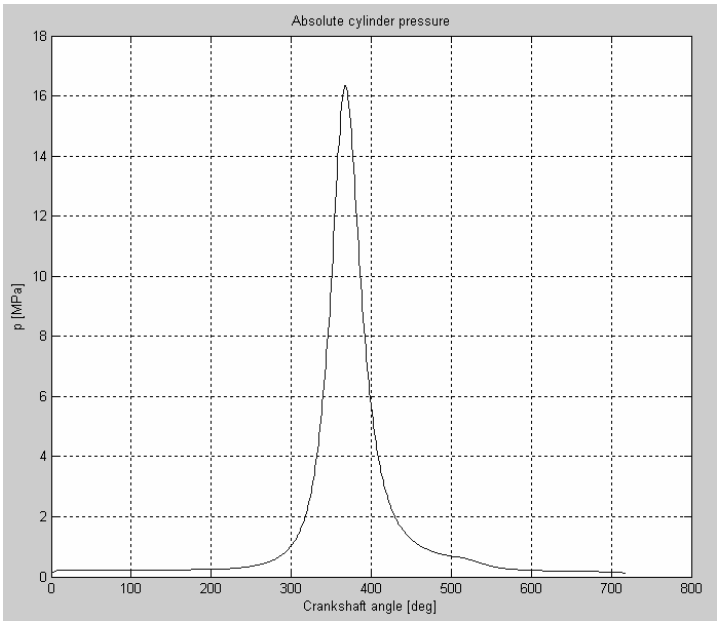

Figure 5: Absolute cylinder pressure [MPa]. 




Figure 6: Instantaneous cylinder volume $\left[\mathrm{m}^{3}\right]$.

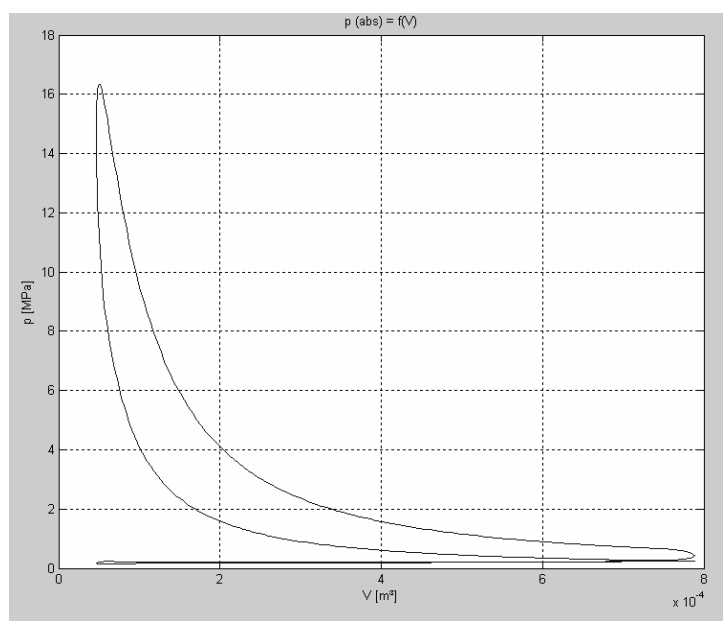

Figure 7: P-V diagram.

The distribution of the mean convection coefficient and the mean gas temperature at the liner is shown on figures 8 and 9 .

At the cylinder head fire deck, the mean values of these boundary conditions during one complete cycle (i.e. $720^{\circ}$ of crank angle) shall be applied.

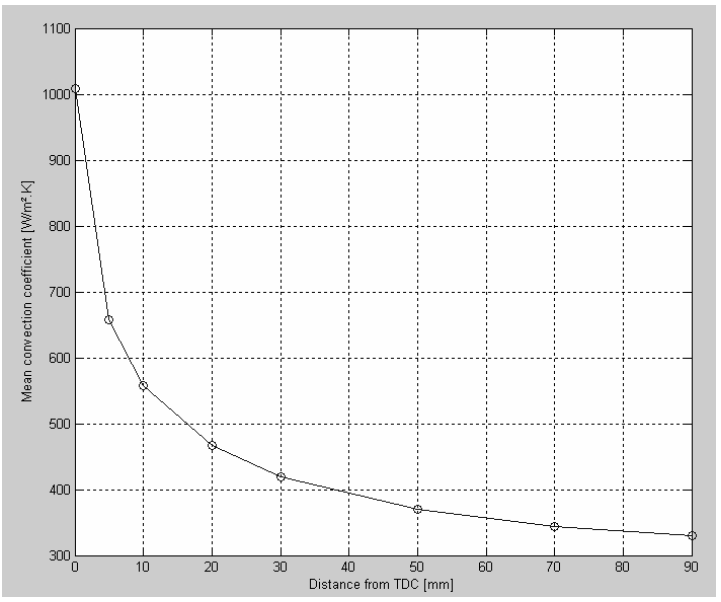

Figure 8: Convection coefficient distribution at cylinder liner.

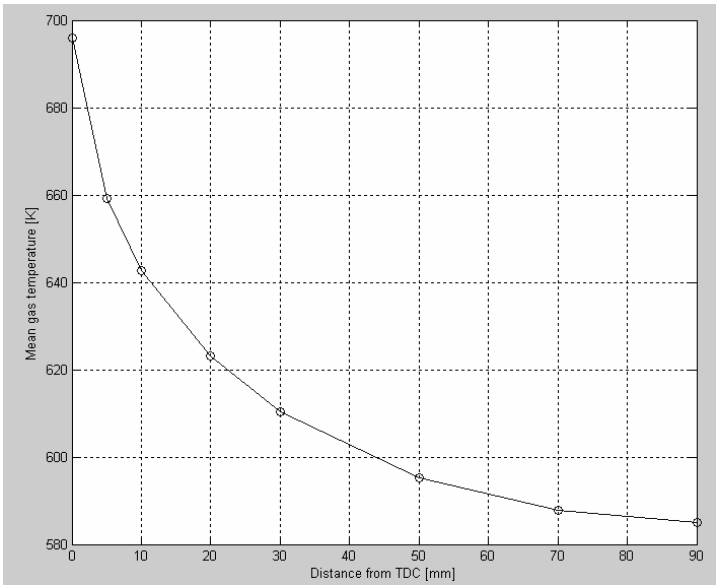

Figure 9: Mean gas temperature distribution at cylinder liner.

Cylinder Head and Crankcase Water Jackets - To determine the heat transfer coefficients (HTC) at the water galleries, it is strongly recommended to perform a Computational Fluid Dynamics (CFD) analysis, due to the complex geometries of these regions.

This kind of analysis can also predict if there are regions which can present stagnant points or low water speed leading to boiling phenomena.

On the opposite side, high water speeds can leads to a pressure drops bellow the vapor pressure at the local temperatures. At this point, bobbles can appear and if the pressure rises to a value where these bobbles can collapse, cavitation phenomena will occur affecting the cylinder head structure.

The CFD analysis is not on the scope of this study, but it is important to note the importance of this kind of verification for cylinder head and crankcase water jackets. 
The next figures present the model which has 1,9 million internal cells at the whole flow domain and the results of the CFD analysis for the considered engine.

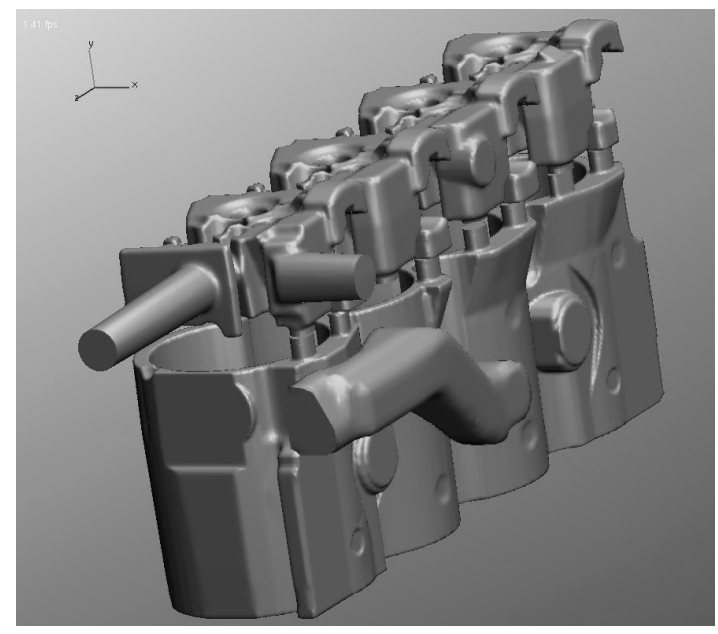

Figure 10: Model for the CFD analysis.



Figure 11: HTCs at the crankcase water jacket.

The obtained results from the CFD analyses indicate that the water jackets are well designed. Thus, no boiling or cavitation will occur for a considered water temperature of 85 to $95^{\circ} \mathrm{C}$.

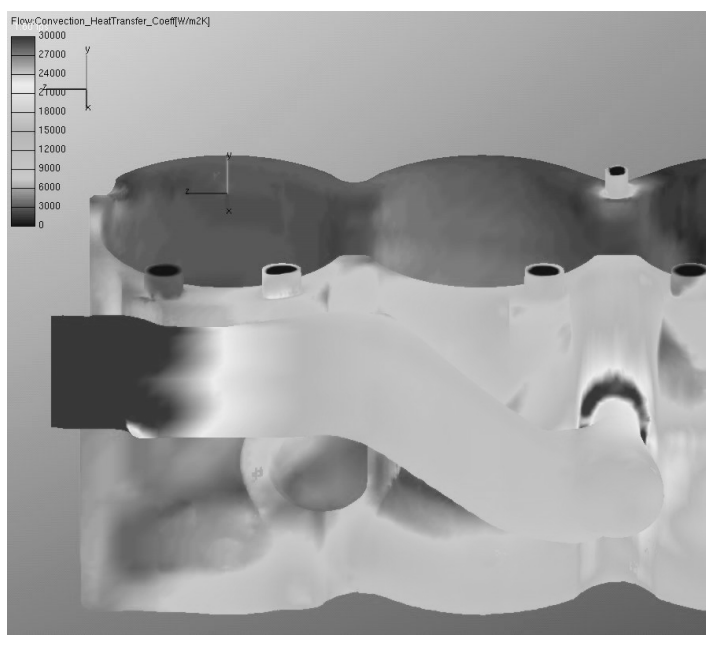

Figure 12: HTCs at the crankcase water jacket.

The calculated HTCs can be transferred to the finite element model for a heat transfer analysis. The nodal temperatures will be evaluated for a subsequent linear static analysis taking into account the thermal stress effects.

VALVE SEATS AND GUIDES PRESS FIT - The maximum load due to the press fit assembly, will be introduced in the model as an expansion temperature simulating the maximum designed interference. For the intake and exhaust valve seats, a radial interference of $54,5 \mu \mathrm{m}$ was considered and for the valve guides, $30 \mu \mathrm{m}$.

MANUFACTURING PROCESS RESIDUAL STRESS - Residual stresses due to casting and quenching heat treatment, were also taking into account for cylinder head stress state calculation. These stresses were obtained from simulations performed by MAGMA®, which is a software dedicated for this propose.

The mathematical model and considered boundary conditions are not in the scope of this paper and by this way, only the final results of the simulations will be presented.

The next figure shows the schematic time vs. temperature considered to simulate the cylinder head heat treatments. 


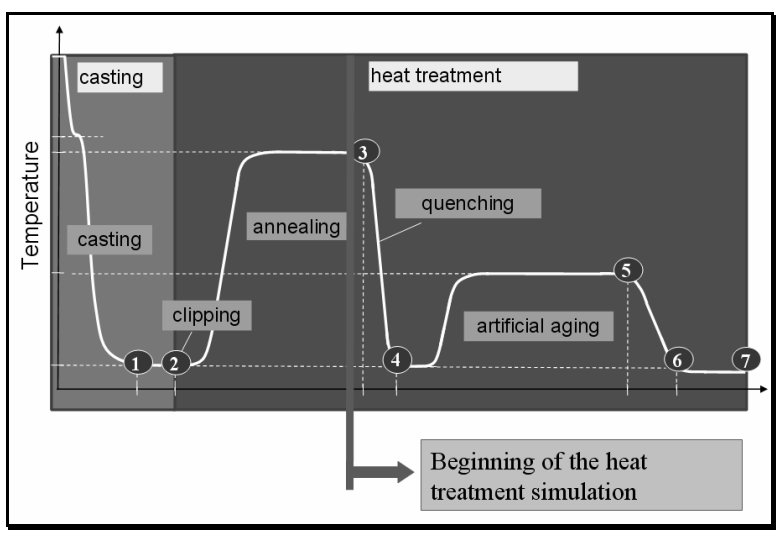

Figure 13: Time vs. temperature heat treatments (Courtesy of MAGMA®).

Figure 14 shows the residual stresses after the machining process of the cylinder head. These stresses will be added to other calculated stresses, considering the correct direction of all stresses for fatigue cycle determination.

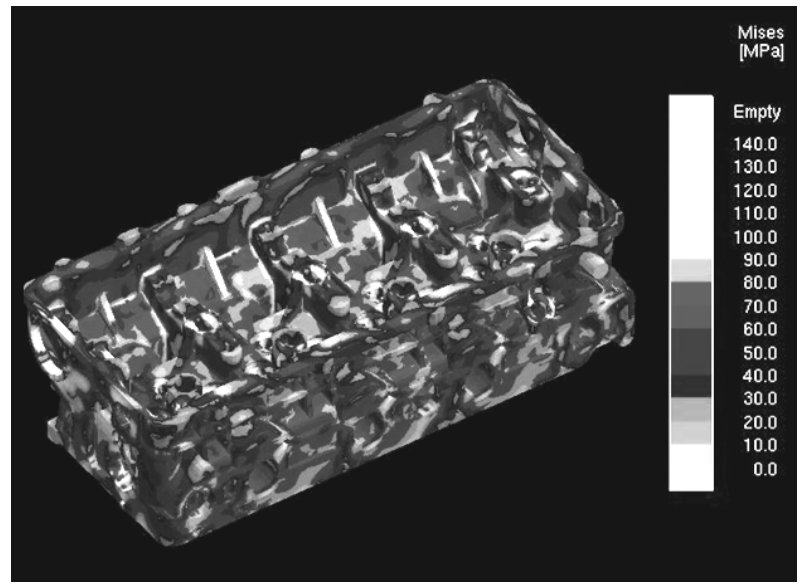

Figure 14: Calculated residual stress distribution (Courtesy of MAGMA®).

The theoretical model was validated by cutting the component in several parts and measuring the residual stresses with gages in specific positions, as showed on figure 15.

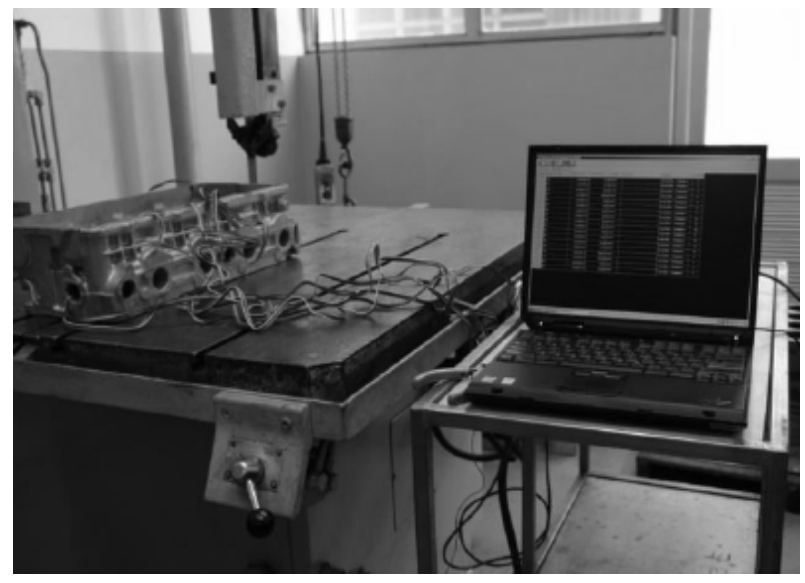

Figure 15: Strain measurements for theoretical model validation.

\section{MATERIAL PROPERTIES}

The next table presents the considered properties for the cylinder head:

Table 1: Cylinder head material properties.

\begin{tabular}{|c|c|}
\hline Tensile Strength $\left(\sigma_{\mathrm{u}}\right)$ & $300 \mathrm{MPa}$ \\
\hline Yield Strength $\left(\sigma_{\mathrm{y}}\right)$ & $286 \mathrm{MPa}$ \\
\hline Compressive Yield Strength $\left(\sigma_{\mathrm{yc}}\right)$ & $290 \mathrm{MPa}$ \\
\hline Modulus of Elasticity $(\mathrm{E})$ & $73000 \mathrm{MPa}$ \\
\hline Poisson's Ratio $(v)$ & 0,33 \\
\hline Coeff. of Thermal Expansion $(\alpha)$ & $21.10^{-6} \mathrm{~m} / \mathrm{m} . \mathrm{K}$ \\
\hline Thermal Conductivity $(\mathrm{k})$ & $160 \mathrm{~W} / \mathrm{m} . \mathrm{K}$ \\
\hline Fatigue Strength $\left(\sigma_{\mathrm{bw}}\right)$ & $95 \mathrm{MPa}$ \\
\hline
\end{tabular}

These properties are based on a heat treated aluminum alloy EN-Al Si7Mg0.6 (A357 T6). The fatigue strength was obtained considering a probability of failure of $10 \%$ at a confidence level of $95 \%$. For the crankcase, the properties of the gray cast iron EN-GJL 250 were considered.

\section{COVER FACTOR}

As a guideline, the relation between the tightening force generated by all cylinder head bolts and the maximum force generated at the cylinder head bottom face area due to the combustion, shall be at least 2,50.

There are some engines running with lower cover factors and no gas leakage. The gas sealing depends on the 
cylinder head, crankcase and gasket stiffness and to check this functionality, it is necessary to perform a nonlinear analysis including the gasket loading and unloading characteristic curves. This is out of the scope of this paper. The cover factor can be determined as follow:

$$
C f=\frac{n \cdot F a p}{\frac{\pi \cdot d p^{2}}{4} \cdot p}
$$

Where: $n=$ number of active cylinder head bolts

Fap $=$ residual tightening force of the bolts $\mathrm{dp}=$ cylinder diameter

$\mathrm{p}=$ working combustion peak pressure

In our case, the cover factor is 3,10 so, no gas leakage is expected.

\section{FATIGUE STRENGTH VERIFICATION}

The theory used to verify the fatigue strength of the component is based on the high cycle fatigue, considering that the cylinder head shall resist up to $1,58.10^{8}$ cycles. This number of cycles was determined considering an expected durability for $300.000 \mathrm{~km}$ at an average speed of $65 \mathrm{~km} / \mathrm{h}$ and a load factor of $30 \%$.

The next picture shows the S-N curve obtained from a rotating beam fatigue test, considering specimens removed from a region close to the critical area.

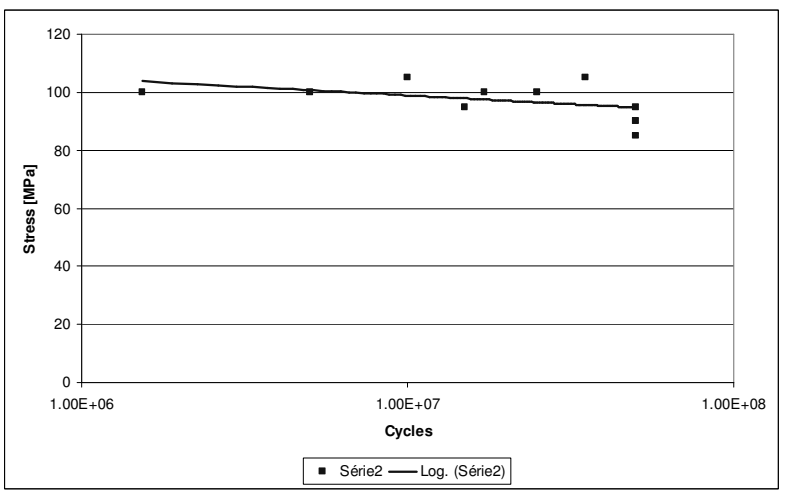

Figure 16: Experimental S-N curve for EN-Al Si7Mg0.6

FATIGUE STRENGTH MODIFYING FACTORS Considering the fatigue strength obtained from a standard test specimen, it is possible to estimate the actual fatigue strength considering the equation bellow:

$$
\sigma_{b w}=k a \cdot k b \cdot k c \cdot k d \cdot k e \cdot k f \cdot \sigma_{b w}{ }^{\prime}
$$

Where:

$$
\sigma_{\mathrm{bw}}=\text { actual fatigue strength }(95 \mathrm{MPa})
$$

$$
\begin{aligned}
& \mathrm{ka}=\text { surface finish factor }(0,933) \\
& \mathrm{kb}=\text { size factor }(0,933) \\
& \mathrm{kc}=\text { loading factor }(1,0) \\
& \mathrm{kd}=\text { temperature factor }(1,0) \\
& \mathrm{ke}=\text { reliability factor }(0,868) \\
& \mathrm{kf}=\text { miscellaneous factors }(1,0) \\
& \sigma_{\mathrm{bw}}{ }^{\prime}=\text { fatigue strength of the rotating beam specimen }
\end{aligned}
$$

The fatigue modifying factors of the cylinder head were determined taking into account specific design characteristics of the component.

Thus, $\sigma b w^{\prime}=73,6 \mathrm{MPa}$ (for $5.10^{7}$ cycles)

The determination of these factors can be verified in reference [6].

FATIGUE CYCLE - The critical fatigue cycle for the cylinder head can be determined considering the following load cases:

1) Combustion load: Combustion peak pressure + Bolt preload + Thermal stress + Valve guides and seats press fit + Residual stress.

2) Bolt assembly: Bolt preload + Thermal stress + Valve guides and seats press fit + Residual stress.

These load cases shall be taken into account considering the critical engine operating condition. In this case, the maximum engine power.

MULTIAXIAL FATIGUE APPROACH - Due to the multiaxial proportional loading at the cylinder head, the Sines method will be considered for the fatigue analysis. This procedure shall consider all alternating stresses (normal and shear) at all nodes of the finite element model. This methodology can be fully verified at the reference [4]. The stress amplitude can be determined according to the next equation:

$$
\bar{\sigma}_{a}=\frac{1}{\sqrt{2}} \cdot \sqrt{\left(\sigma_{x a}-\sigma_{y a}\right)^{2}+\left(\sigma_{y a}-\sigma_{z a}\right)^{2}+\left(\sigma_{z a}-\sigma_{x a}\right)^{2}+6 \cdot\left({\tau_{x y a}}^{2}+\tau_{y z a}{ }^{2}+\tau_{z x a}{ }^{2}\right)}
$$

The mean stress is obtained as follow:

$$
\bar{\sigma}_{m}=\sigma_{x m}+\sigma_{y m}+\sigma_{z m}
$$

The equivalent completely reversed stress, i.e., zero mean stress is computed considering the Smith-Watson- 
Toper (SWT) criterion. Nowadays, this fatigue criterion is considered as being the best methodology for aluminum alloys.

$$
\sigma_{a r}=\sqrt{\left(\bar{\sigma}_{a}+\bar{\sigma}_{m}\right) \cdot \bar{\sigma}_{a}}
$$

The number of cycles until failure, that the component should resist, is calculated as follow:

$$
N f=\frac{1}{2} \cdot\left(\frac{\sqrt{\left(\bar{\sigma}_{a}+\bar{\sigma}_{m}\right) \cdot \bar{\sigma}_{a}}}{\sigma^{\prime} f}\right)^{\frac{1}{b}}
$$

Where: $\quad \sigma^{\prime} f=$ high cycle fatigue coefficient $\mathrm{b}=$ high cycle fatigue exponent follow:

Finally, the fatigue safety factor can be determined, as

$$
S f=\frac{\sigma_{b w}{ }^{\prime}}{\sigma_{a r}}
$$

The minimum safety factor of the component shall be higher than 1,09 to achieve the specified engine life. The calculations were performed based on the fatigue tests up to $5.10^{7}$ cycles. For $10^{8}$ cycles, no significant differences are expected.

\section{RESULTS OF THE STRUCTURAL ANALYSIS}

The next picture shows the results of the heat transfer analysis. According to these results, it is possible to note that no regions of the cylinder head present temperatures higher than the material permissible one, i.e., $240^{\circ} \mathrm{C}$.

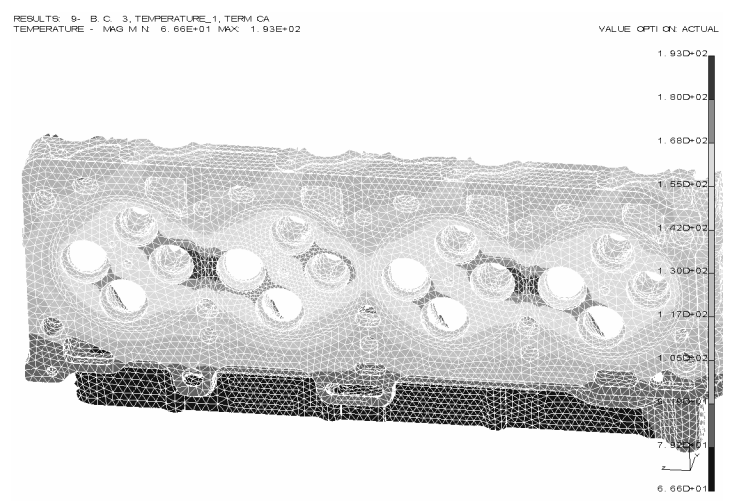

Figure 17: Temperature distribution at the cylinder head.

The linear static analysis results are presented in the next figures. Maximum principal stresses are shown just as reference values.

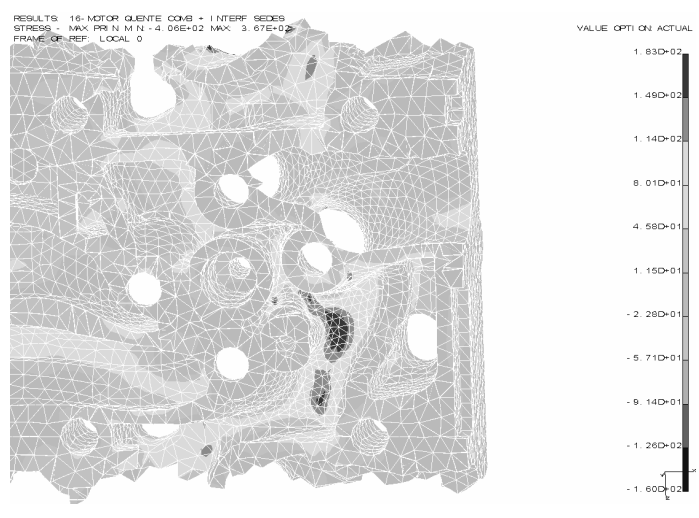

Figure 18: Maximum principal stress due to load case 1.

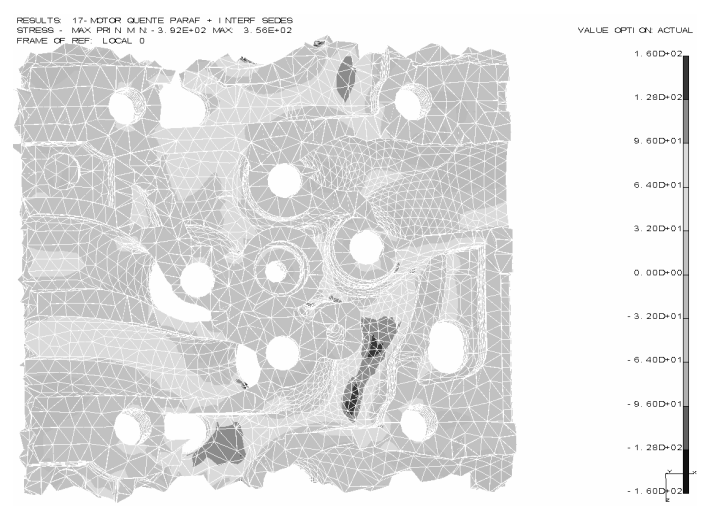

Figure 19: Maximum principal stress due to load case 2.

Considering the SWT criterion for the fatigue analysis, it was determined the following safety factors:



Figure 20:Minimum fatigue safety factor at the upper region. 


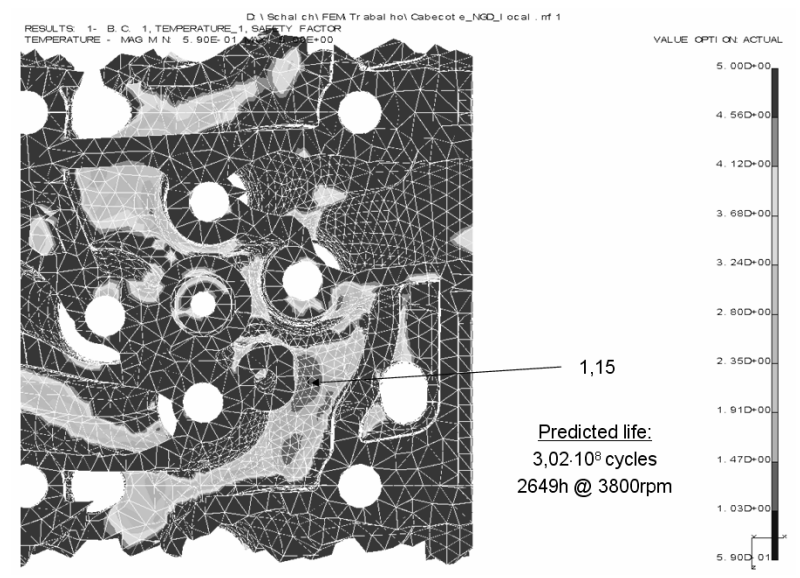

Figure 21: Minimum fatigue safety factor at the fire deck region.

\section{ENGINE CHARACTERISTICS}

- Connecting rod length: $175,4 \mathrm{~mm}$

- Piston diameter: $96 \mathrm{~mm}$

- Piston stroke: $102,5 \mathrm{~mm}$

- Maximum torque: 380 N.m @ 1600 rpm

- $\quad$ Maximum power: $120 \mathrm{~kW}$ @ $3800 \mathrm{rpm}$

\section{CONCLUSIONS}

Cyclic load without considering the thermal effects could be also evaluated, since such loads actually occur during the engine's life. However, the values obtained for that analysis are far below the ones evaluated for "hot" engine. So, in the design criteria are taken into account only the cyclic load with thermal stresses, as defined earlier in this paper.

According to the obtained results, it is possible to verify that the cylinder head will not present structural failures during the operation considering the designed life, because the current safety factor is higher than the minimum required.
Also, neither cavitation nor boiling is expected in the cylinder head and crankcase water jackets.

\section{REFERENCES}

[1] Kreith, F., Principles of heat transfer. Edgard Blücher. $3^{\text {rd }}$ edition, 1977, 550p., cap.7, 8, 9.

[2] Hohenberg, G. F., Advanced approaches for heat transfer calculations. Diesel Engine Thermal Loading SAE Paper 790825. 1979, p.61-79.

[3] Heywood, J. B., Internal combustion engine fundamentals. McGraw-Hill. 1988, Cap.4, ISBN 0-07028637-X.

[4] Dowling, N. E., Mechanical behavior of materials, Prentice Hall. 1998, ISBN 0-13-905720-X.

[5] Norton, R. L., Machine design. An integrated approach, Prentice Hall. 2000, ISBN 0-13-017706-7.

[6] Shigley, J. E., Mischke, C. R., Budynas, R. G., Mechanical Engineering Desing, Mc Graw Hill. 2004, ISBN 0-07-252036-1.

[7] Taylor C. F., The internal combustion engine in theory and practice. MIT Press. 1985, v.1, ISBN 0-26270026-3.

[8] Taylor C. F., The internal combustion engine in theory and practice. MIT Press. 1985, v.2, ISBN 0-26270027-1

[9] Bosch, Automotive handbook, $S A E, 25^{\text {th }}$ edition, 2004, p.498-505. 